\title{
Functional Outcome of Distal End Radius Fractures after surgery: A Follow Up Study.
}

${ }^{*}$ Dr. Prabu.M, **Dr. SushmaChandrashekar\& ***Ms.RammuanpuiiPaihte

\section{Abstract:}

This study is a post-operative follow up study conducted with multiple observations in Kempegowda Institute of Medical Sciences and Research Center, Bangalore, .The study included 30 cases of distal end radius fractures that were operated with the closed reduction and uniplanar external fixator augmented with $k$-wire for distal end radius by the principal of ligament taxis. Functional outcome was assessed using modified Green O'Brien score at each follow up visit. Results: In our study, 14 (46.6\%) patients had excellent results. Whereas, 11 (36.7\%) patients had good results and 3 (10\%) had fair and only 2 (6.7\%) patients had poor results. Most of the fractures united by 12 weeks. Complications associated with the study was stiffness, malunion, sudeck'sosteodystrophy and pin tract infection. Conclusion: The uniplanar external fixator augmented with $k$-wire is a good choice in the treatment of distal end radius fractures in terms of providing a good functional outcome.

\section{INTRODUCTION}

Distal end radius fractures is one of the most common fractures of the upper limb especially in the elderly population, accounting for about $17 \%$ of all upper limb fractures ${ }^{(1)}$ Surgical stabilization of these fractures remains a challenge even today. In this study, we focus on the functional outcome of distal end radius fractures treated by closed reduction fixation with uniplanar external fixator augmented with kirschner wire at 6,12 \&25 weeks

\section{Need of the study \& Review of literature}

Fractures of the distal radius have been discussed in Orthopaedic literature for over 200 years. The fracture patterns were described even before the advent of radiography.
Although Pouteau, a French surgeon may have described this fracture pattern earlier [2]

Abraham Colles is generally credited with description of the most common fracture pattern affecting the distal end radius. "Colles" fracture refers only to extra articular fractures with dorsal displacement of the distal fragment[3]

Clyburn T.A (1987) ${ }^{[4]}$ described a new dynamic external fixation that allows controlled wrist movement and full movements of fingers. This early wrist mobility facilitates very early rehabilitation and has afforded excellent results. Clyburn agrees that the best results are obtained when combined with limited internal fixation especially for a 'diepunch' or radial styloid fragment 
Richard A. Rogachejsky et al, (2001) demonstrated that severe comminuted intra- articular fractures of the distal radius should be treated by open reduction and combined internal and external fixation. The combined technique, supplemented by bone grafting and plate fixation as needed, is a satisfactory treatment [5]

Peter M.Murray. (2002) reviewed their preferred technique of using the external fixator as a neutralization device rather than as a traction device. The absence of sustained radiocarpal traction during distal radius fracture healing may facilitate and help avoid the complications associated with sustained longitudinal traction $(6)$

David Ring, et al., (2004) evaluated 25 patients with AO C3-2 fractures treated with combined dorsal and volar plate fixation at an average of 25 months after injury and concluded that combined dorsal and volar plate fixation can achieve a stable, mobile wrist in patients with very complex fractures[7]. The results were limited by the severity of injury and deteriorated with longer follow up. A second operation for implant removal was common, and there was a small risk of tendon related complications.

\section{OBJECTIVES:}

- To describe the characteristics of the study subjects.

- To find out the functional outcome in subjects who had undergone the surgery.

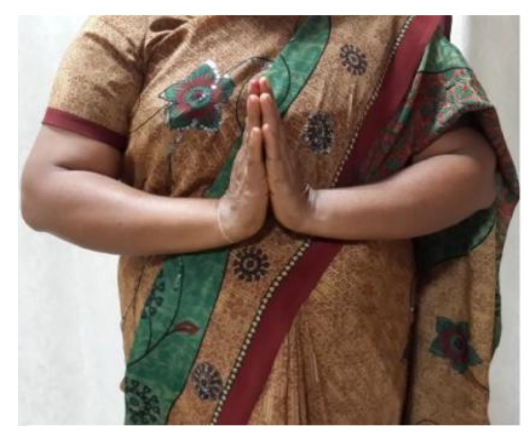

DORSIFLEXION

\section{METHODOLOGY:}

Quantitative research approach was applied for the study. PreExperimental Research Design with One Shot case design was used for this study. The study was conducted at Kempegowda Institute of Medical Sciences and Research Center. Bangalore. The target population of the study was 30 who had undergone closed reduction and uniplanar external fixator augmented with k-wire for distal end radius were selected by Purposive sampling technique. The data were analysed by using descriptive and inferential statistics like frequency, percentage, mean, standard deviation, paired T-Test and Chi-Square test.

\section{Inclusion criteria:}

- $\quad$ Age group of 20-70yrs

- $\quad$ Post-operative patients who had distal end radius fracture that were operated with the closed reduction

\section{Exclusion criteria:}

- Those who had complication of surgery post operatively.

\section{Tool}

Part 1: Socio demographic and clinical sheet.

Part 2: Modified GREEN O'BRIEN SCALE

CASE ILLUSTRATION NO 4

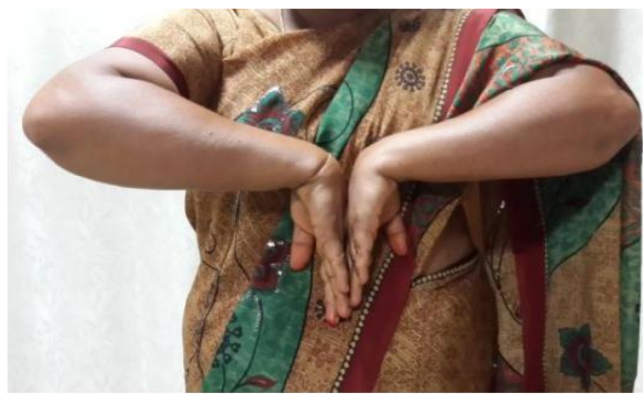

PALMARFLEXION 


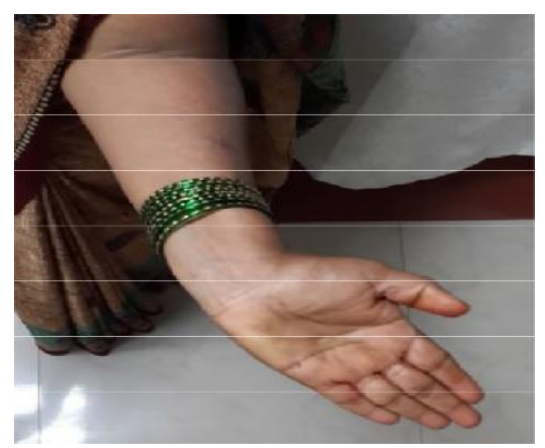

RADIAL DEVIATION

PRE OP X RAY

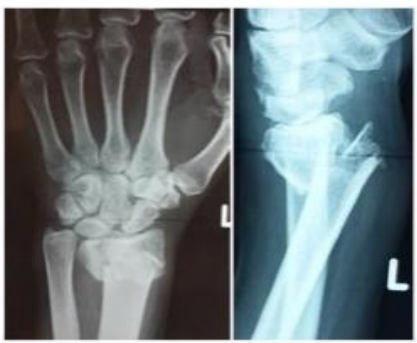

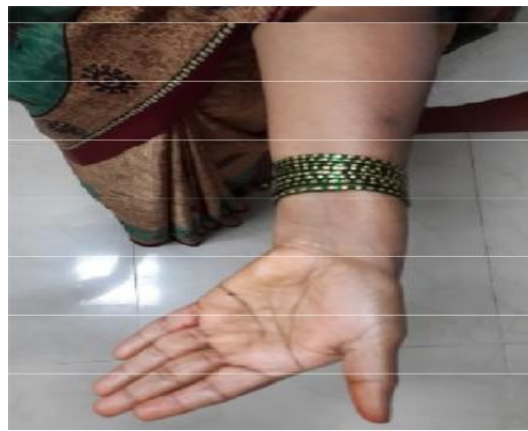

ULNAR DEVIATION

IMMEDIATE POST OP X RAY

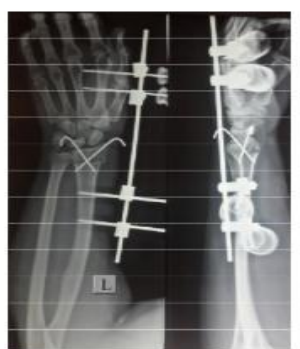

\begin{tabular}{|c|c|c|}
\hline NO. OF WEEKS & FREQUENCY & PERCENTAGE \\
\hline 0-6 WEEKS & 0 & 0 \\
\hline 7-12 WEEKS & 20 & 66.66 \\
\hline 13-18WEEKS & 10 & 33.33 \\
\hline 19-24 WEEKS & 0 & 0 \\
\hline >24 WEEKS & 0 & 0 \\
\hline TOTAL & 30 & 100 \\
\hline
\end{tabular}

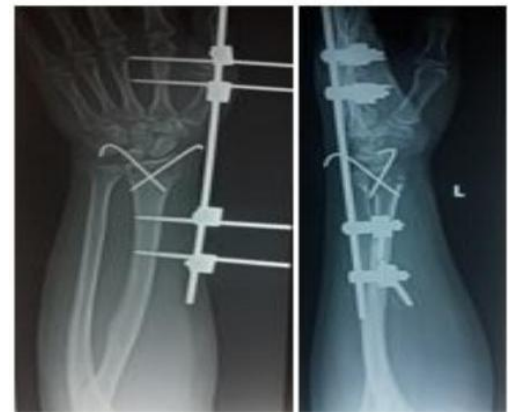

6 WEEKS FOLLOW-UP

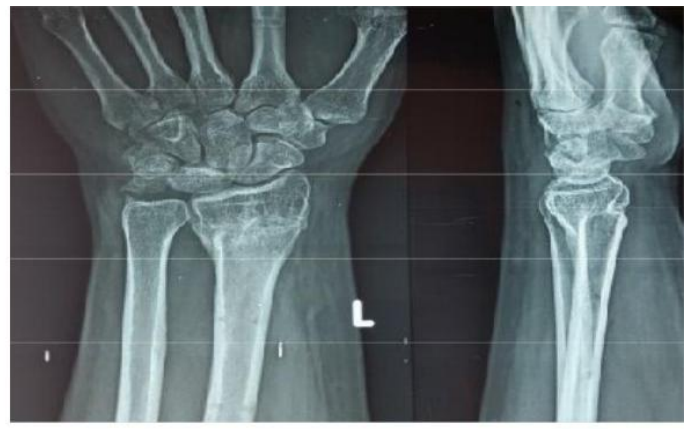

24 WEEKS FOLLOW UP 
Table 1: Time Taken for Union $\mathrm{N}=\mathbf{3 0}$

In our study, the Mean time for union was 14 weeks with a standard deviation of 2.87 weeks with most fractures uniting by $12^{\text {th }}$ week and the longest being $18^{\text {th }}$ week

Table 2: Functional Outcome according to Modified Green O'Brien Score

\begin{tabular}{|c|c|c|}
\hline $\begin{array}{c}\text { MODIFIED GREEN } \\
\text { AND } \\
\text { O'BRIEN SCORE }\end{array}$ & \multicolumn{2}{|c|}{ 24 WEEKS } \\
\cline { 2 - 3 } EXMBellent & 14 & PERCENTAGE (\%) \\
\hline Good & 11 & 46 \\
\hline Fair & 3 & 37 \\
\hline Poor & 2 & 10 \\
\hline Total & 30 & 7 \\
\hline
\end{tabular}

FUNCTIONAL OUTCOME ACCORDING TO MODIFIED GREEN O'BRIEN SCORE

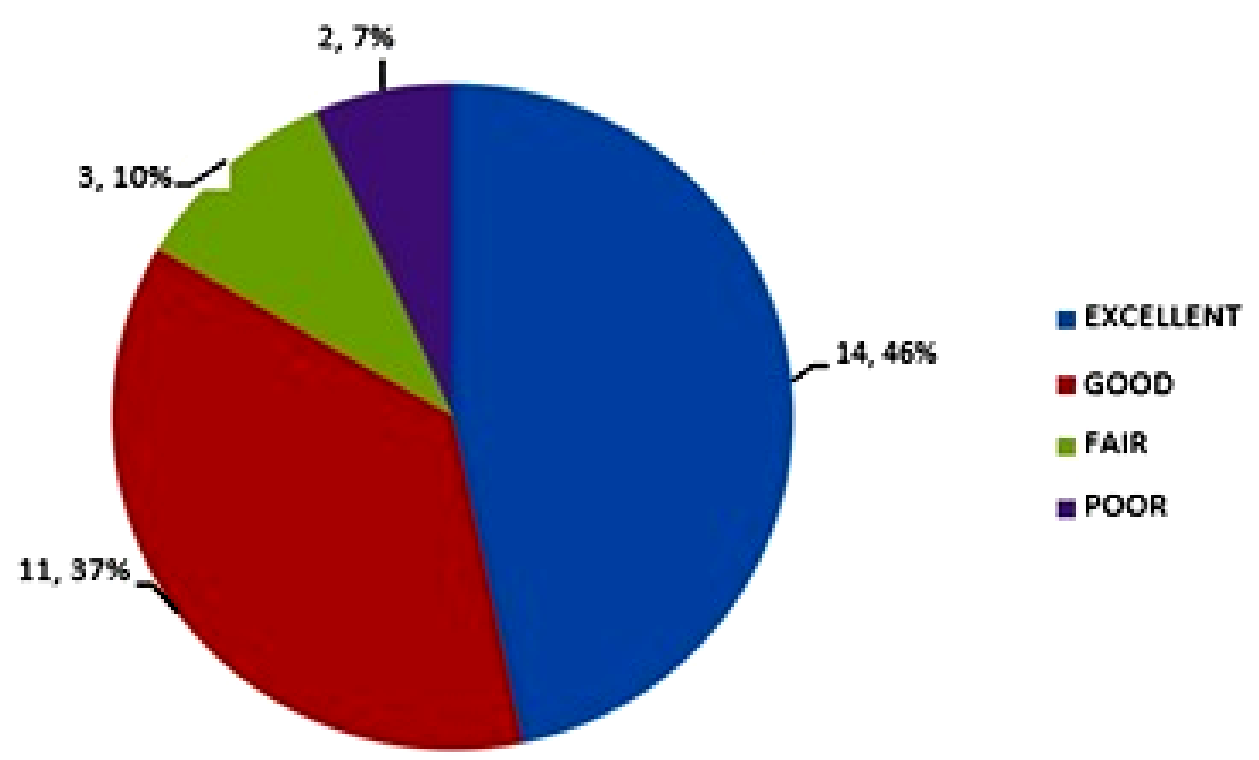

The above table 4 and Graph 3 show that 14 patients had excellent results. Whereas, 11 had good and 3 had fair and only 2 patients had poor results. 
Functional Outcome According to Modified Green O'Brien Score

Table: Comparison of Functional Outcome

\begin{tabular}{|c|c|c|c|}
\hline STUDY & $\begin{array}{c}\text { Sample } \\
\text { size }\end{array}$ & $\begin{array}{c}\text { Excellent + good } \\
(\%)\end{array}$ & $\begin{array}{c}\text { Fair }+ \text { poor } \\
(\%)\end{array}$ \\
\hline Present series & 30 & 83.4 & 16.6 \\
\hline D'Anca (1984)62 & 87 & 94 & 6 \\
\hline Cooney (1979) & 60 & 87 & 13 \\
\hline Steffen (1994) ${ }^{64}$ & 55 & 75 & 25 \\
\hline Pietersen (1991) ${ }^{58}$ & 115 & 83 & 17 \\
\hline
\end{tabular}

Table 5 depicts the comparison of functional outcome of the present study findings with the previous studies, 14 patients had excellent results. Whereas, 11 had good and 3 had fair and only 2 patients had poor results. With excellent + good group accounting for $83.4 \%$ of the study.

\section{DISCUSSION:}

In our study, the mean age of patients was 40.1 years, with the youngest being 21 years and the oldest being 68 years, majority being in the 20-29 and 50-59 age group.The number of male patients in our series were 20 and females were 10. i.e. ( $67.7 \%$ vs $33.3 \%$ ).In our study, 14 (46.4\%) patients had excellent results. Whereas, 11 (36.6\%) had good and $3(10 \%)$ had fair and only $2(6.6 \%)$ patients had poor result.In our study, the Mean time for union was 14 weeks with a standard deviation of 2.87 weeks with most fractures uniting by 12 th week and the longest being 18th week.

\section{CONCLUSION:}

Distal end radius fractures are a very common entity encountered by orthopaedicians worldwide in the emergency department. Even though the recent trend is towards open reduction and internal fixation, the external fixator itself has its own advantages and indications for surgery. In our study, 83.4\% ( $\mathrm{n}=25)$ patients had well to excellent results according to the Green O'Brien score.Hence, we like to conclude that the fractures of the distal end radius can be managed with the uniplanar external fixator augmented with k-wires, if proper preoperative planning, good reduction and surgical technique are followed, leading to high rate of bone union, minimal soft tissue damage and complications. 


\section{REFERENCES:}

1) Colles A.On the fracture of the carpal extremity of the radius.Edinburgh Med Surg 1814; 10:182-6.

2) US Department of Commerce EaSA, Bureau of the Census. Bureau of the Census: Statistical abstract of the United States. 1995

3) Patel M. Two Lyonese Surgeons of the 18th Century: Claude Pouteau and Marc-Antonie Petit. Prog Med (Paris).1959; 87:337-341.

4) Coles, A.: On the Fracture of the Carpal Extremity of the Radius. Edinb. Med. Surg. J., 10:182-86, 1814.

5) Bar tosh RA, Saldana MJ. Intrarticular fractures of the distal radius: a cadaveric study to determine if ligamentotaxis restores radiopalmar tilt. J Hand Surg [Am] 1990; 15(1):1821

6) Anderson JT, Lucas GL, Buhr BR. Complications of treating distal radius fractures with external fixation: a community experience. Iowa Orthop J 2004; 24: 53-59.

7) Winemaker MJ, Chinchalkar S, Richards RS, et al. Load relaxation and forces with activity in Hoffman external fixators: a clinical study in patients with Colles' fractures. J Hand Surg 1998; 23A:926-932.

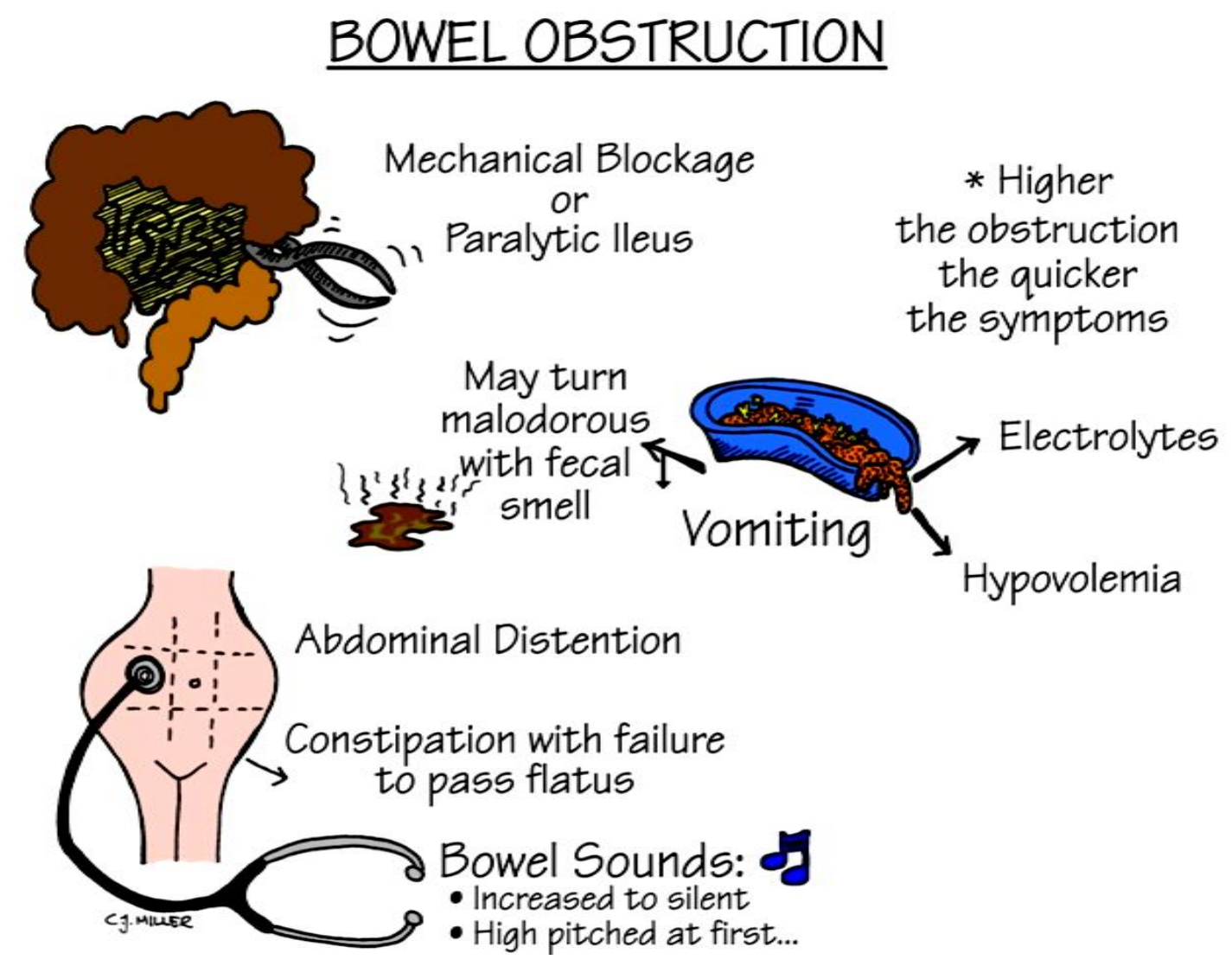

